\title{
Characterization of PAR1 and FGFR1 expression in invasive breast carcinomas: Prognostic significance
}

\author{
MARTA TIBURCIO $^{1}$, SANDRA M.A. COSTA ${ }^{1}$, MARIA DE FATIMA DUARTE ${ }^{2,3}$, \\ FERNANDO C. SCHMITT ${ }^{4,5}$ and ADHEMAR LONGATTO FILHO ${ }^{1,6}$
}

\begin{abstract}
${ }^{1}$ Life and Health Sciences Research Institute (ICVS), School of Health Sciences, University of Minho, Braga; ICVS/3B's - PT Government Associate Laboratory, Braga/Guimarães; ${ }^{2}$ Centro de Biotecnologia Agrícola e Agro-Alimentar do Baixo Alentejo e Litoral (CEBAL)/ Instituto Politécnico de Beja (IPBeja), Beja; ${ }^{3}$ Centre for Research in Ceramics \& Composite Materials (CICECO), University of Aveiro, Aveiro; ${ }^{4}$ Medical Faculty, Department of Pathology, University of Porto; ${ }^{5}$ IPATIMUP - Institute of Molecular Pathology and Immunology, University of Porto, Porto, Portugal;

${ }^{6}$ Laboratory of Medical Investigation (LIM) 14, Faculty of Medicine, University São Paulo, São Paulo, Brazil
\end{abstract}

Received January 16, 2012; Accepted March 21, 2012

DOI: $10.3892 / \mathrm{ol} .2012 .806$

\begin{abstract}
Breast cancer is the most common cause of cancer mortality among women worldwide. Among the several factors associated with breast cancer development, angiogenesis plays an essential role and has currently emerged as a potential diagnostic, prognostic and therapeutic target. Protease-activated receptor 1 (PAR1) and fibroblast growth factor receptor 1 (FGFR1) have important activities in tumor angiogenesis and progression. The aim of this study was to investigate the prognostic significance of these two receptors, hypothesising significant correlations between receptor expression in tumor angiogenesis and clinicopathological parameters customarily used in breast cancer prognosis and prediction. Formalin-fixed and paraffin-embedded samples of ductal invasive breast carcinomas were used to analyze the expression of PAR 1 and FGFR1, in the tumor cells as well as in the tumor stroma, and further determine intratumoral microvessel density (iMVD) to quantify intratumoral angiogenesis. Correlations between PAR1 and FGFR1 expression in tumor cells and stroma, iMVD and several clinicopathological parameters and molecular markers used in breast cancer diagnosis have been addressed. The correlation between PAR1 and FGFR1 suggests an association of the two receptors with a more aggressive breast cancer phenotype and, consequently, a potential role during tumor progression. The results reported in the present study also emphasize the importance of microenvironmental factors in tumor progression, while precluding the positive association between iMVD and breast cancer aggressiveness.
\end{abstract}

Correspondence to: Professor Adhemar Longatto Filho, Laboratory of Medical Investigation (LIM) 14, Faculty of Medicine, University São Paulo, São Paulo 1246-903, Brazil

E-mail: longatto16@hotmail.com

Key words: protease-activated receptor 1, fibroblast growth factor receptor 1 , invasive breast cancer

\section{Introduction}

Breast cancer is a heterogeneous disease characterized by uncontrolled growth and spread of abnormal cells, being the most common cause of cancer mortality among women worldwide (1). Invasive breast cancer is the most common type of carcinoma in women, accounting for $22 \%$ of all female cancers and comprises a heterogeneous group of malignant epithelial tumors, characterized by the invasion of adjacent tissues and a marked tendency to metastasize to distant sites, differing with regard to their clinicopathological features and biological potential (2). The invasive ductal carcinoma of no specific type (IDC-NST) is the most common invasive breast cancer, accounting for $40-75 \%$ of all invasive tumors and is a histologically diverse group of lesions which includes all carcinomas that cannot be subclassified into one specialized type (3). Carcinogenesis is a multistep process mostly characterized by the accumulation of genetic alterations that drive normal cells to malignant transformation (4). The majority of genes correlated with breast cancer development are also involved in pathways linked to the regulation of crucial biological processes such as proliferation, apoptosis, angiogenesis, invasion and metastasis (5). Angiogenesis is involved in the development and progression of malignant tumors enabling cancer cells to acquire an adequate supply of oxygen, metabolites and an effective way to remove waste products, and also provides a pathway for metastases. During tumor angiogenesis, the equilibrium between pro- and anti-angiogenic factors is lost and their relative contribution may change according to tumor type, tumor localization, as well as with tumor growth, regression and relapse. Pro- and anti-angiogenic molecules are released from tumor cells, endothelial cells (ECs), blood cells and the extracellular matrix. Among these factors, PAR1 and FGFR1 are key contributors to the angiogenic process (6-8).

Protease-activated receptors (PARs) are members of the G-protein coupled receptors (GPCR) superfamily that are expressed in several tissues by a variety of cells, being activated by proteolytic cleavage of their extracellular domains (9). 
PAR1, one of the four members of the PAR family, is the predominant thrombin receptor in EC and is also detected in a variety of other cell types (10). PAR1 has been described as a crucial factor in angiogenesis, promoting numerous biological effects including coagulation, inflammation, mitogenesis and cell proliferation (11). The role of PAR1 in vascular biology and tissue remodelling is further stressed by the fact that factors activated upon thrombin-induced PAR1 signalling are known to be important during the process of vascular remodelling. The expression and/or release of several growth factors, including FGF2, PDGF, VEGF $(12,13)$, the upregulation of the insulin-growth factor receptor (IGFR)-1 (14), and the activation of fibroblast growth factor receptor 1 (FGFR1) (15) were shown to be induced in response to thrombin, metalloproteinase (MMP) 1 and more recently FGF1 (13). Accumulating evidence suggests that the receptor PAR1 modulates cell proliferation and motility in physiopathological cell invasion processes, suggesting a role in initiating cancer growth and metastasis (16). Overexpression of this receptor has been detected in numerous human cancers, including breast cancer, where it has been described as being preferentially expressed in high-grade human breast carcinoma, correlating with the degree of invasiveness with differential metastatic potential (16). Moreover, there is evidence of the presence of PAR1 protein and mRNA not only in human malignant tumor cells, but also on the cell types forming the tumor microenvironment (17).

FGFR1 is a member of the FGFRs family (FGFR 1-4), a family of tyrosine kinase receptors, responsible for mediating a number of actions induced by the members of the fibroblast growth factor family (FGF 1-24) group of proangiogenic factors playing critical functions in each step of the angiogenic cycle. Aberrant regulation of FGF ligands and their receptors has been associated with prostate and breast tumorigenesis (18). Studies using inducible FGFR1 (iFGFR1) suggest that it is able to directly activate both proliferation and survival signals (antiapoptotic effects) within the mammary epithelium to rapidly induce hyperplastic lesions and regulate MMP secretion. Furthermore, the signalling complexity related to the iFGFR1-induced lesions, including the loss of myoepithelium and increased vascular branching suggest that other indirect effects mediated through stromal interactions also contribute to the tumor invasive phenotype (19). The aim of this study was to investigate the expression of PAR1 and FGFR1 in tumor cells and cells from the tumoral microenvironment in a series of invasive breast cancers and explore possible significant correlations with intratumoral microvessel density (iMVD), several breast cancer clinicopathological parameters and molecular markers.

\section{Materials and methods}

Tissue samples. A retrospective series of 224 formalin-fixed paraffin-embedded samples of ductal invasive breast carcinomas were used to construct tissue microarrays. The series of ductal invasive breast carcinomas had previously been characterized regarding clinicopathological parameters, such as histological grade, lymph node metastasis and patient survival (20). Samples from each case were collected from the donor sample with a $1 \mathrm{~mm}$ gauge cylinder and transferred to a receptor block using a manual tissue microarrayer (TMA) (Beecher Instruments, Sun Prairie, WI, USA). TMA sections (3 $\mu \mathrm{m}$ ) were cut from the receptor block and processed as described in a previous study (20). Most of the immunohistochemical characterization was previously reported and included the evaluation of several molecular markers, including estrogen receptor (ER), progesterone receptor (PR), epidermal growth factor receptor (EGFR) 2 (HER2), EGFR, P-cadherin (Pcad), keratin (CK) 5, CK14, P63, P53 and vimentin (20).

PARl and FGFR1 immunohistochemistry. Immunohistochemical staining for PAR1 was carried out using Dako EnVision polymer (Dako Coorporation, Carpinteria, CA, USA) and the monoclonal antibody PAR1 (Thrombin R ATAP2: sc-13503 Santa Cruz Biotechnology, Inc., Santa Cruz, CA, USA). Deparaffinized and re-hydrated TMAs were immersed in $1 \mathrm{mM}$ EDTA buffer solution with $0.05 \%$ Tween 20 , pH 7.4, and heated at $98^{\circ} \mathrm{C}$ for $30 \mathrm{~min}$ in a bath. Following washing in phosphate-buffered saline (PBS), slides were incubated with $3 \%$ hydrogen peroxide in methanol for $10 \mathrm{~min}$, washed in PBS again and covered with a blocking serum for $10 \mathrm{~min}$, prior to incubation with the primary antibody diluted at 1:100, overnight at room temperature. Sections were sequentially washed in PBS, incubated with the polymer conjugated with secondary antibodies for $10 \mathrm{~min}$ and finally with 3,3'-diaminobenzidine (DAB Substrate System; Lab Vision Corporation, Fremont, CA, USA) for $10 \mathrm{~min}$, between washes with PBS. TMAs were then counterstained with haematoxylin, dehydrated and mounted with the synthetic mounting medium Entellan (Merck, Darmstadt, Germany).

Immunohistochemical staining for FGFR1 was performed using the streptavidin-biotin peroxidase technique (LabVision Corporation) and the polyclonal antibody anti-FGFR1 (Flg C-15: sc-121 Santa Cruz Biotechnology, Inc.), raised against the C-terminus of the human form. TMAs were deparaffinized and rehydrated and heat-induced antigen retrieval was performed using a citrate buffer solution $(10 \mathrm{mM})$ with $0.05 \%$ of Tween 20, pH 6.0, for $15 \mathrm{~min}$ in a microwave at 600 Watts. Following washing with PBS, the slides were incubated in a $3 \%$ hydrogen peroxide solution in methanol for $10 \mathrm{~min}$ to block endogenous peroxidase activity. The slides were then incubated with a blocking serum for $10 \mathrm{~min}$ and then for $2 \mathrm{~h}$ at room temperature with the primary antibody at 1:200 dilution. Slides were incubated with biotinylated goat anti-polyvalent antibody for $10 \mathrm{~min}$, streptavidin peroxidase for another $10 \mathrm{~min}$ and 3,3'-diaminobenzidine (DAB Substrate System; Lab Vision Corporation) for a further $10 \mathrm{~min}$, between washes with PBS. TMAs were counterstained with haematoxylin, dehydrated and mounted with synthetic mounting medium Entellan (Merck).

Immunohistochemical staining in tumor cells and tumor stroma was independently assessed by two skilled pathologists. Discrepancies were resolved by observation through a double-head microscope. Assessment of the immunohistochemical results was based on a semiquantitative evaluation as specified in advance. The stroma of the tumors was classified as negative or positive, according to the presence or absence of positive expression for the two receptors in fibroblasts. The classification of positive immunoreactivity in tumor cells was carried out according to the percentage of immunopositive 


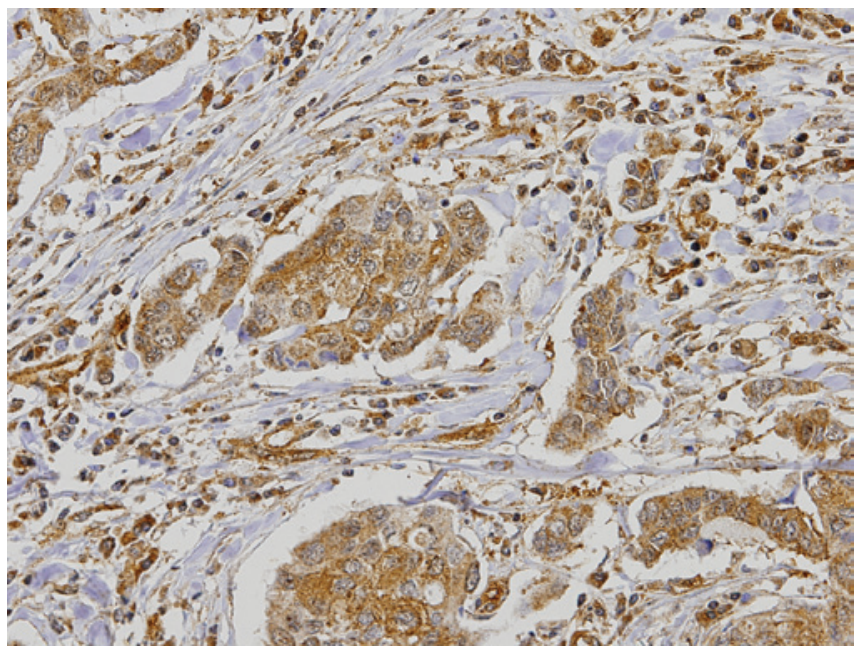

Figure 1. Positive PAR1 immunostaining was observed. PAR1 immunoreactivity was detected in the cytoplasm of the tumor cells (positive $>50 \%$ ), in the endothelial cells and stroma cells (magnification, $\mathrm{x} 20$ ).

cells: $<10 \%$ was classified as negative; positive cytoplasmic immunostaining of PAR1 and FGFR1 ranged from 11 to $50 \%$ and from 51 to $100 \%$, respectively.

Intratumoral microvessel density evaluation. iMVD was evaluated according to the cytoplasmic staining in blood endothelial cells. Evaluation of positive reactions was performed by counting positive anti-factor VIII blood vessels, surrounding a visible lumen clearly separated from adjacent microvessels and from other connective tissue components. Packed vessels were considered as one vessel unit. Analysis was performed at a magnification of x200 (x20 objective lens and x10 ocular lens). An average of 10 hot spot fields was defined as iMVD. Counting of the vonWillebrand factor (anti-factor VIII) immunohistochemical reactions was performed blindly.

Statistical analysis. For statistical analysis, contingency tables and Chi-square testing was performed using StatView 5.0 (SAS Institute Inc., Cary, NC, USA) to estimate the relationship between staining patterns of the different antibodies used. Survival curves were generated by the Kaplan-Meier method, using the SPSS 11.5 statistical software for patients with $>2$ years survival. Two values were considered significantly different when $\underline{\mathrm{P}}<0.05$.

\section{Results}

PAR1 expression. Among the 224 cases, 211 were eligible for statistical analysis. Expression of PAR1 in the tumor demonstrated $2.4 \%$ negative cases, $8 \%$ positive $<50 \%$ and $89.6 \%$ positive $>50 \%$ (Fig. 1). PAR1 expression was also analysed in the stroma of the tumor, where $40.8 \%$ of the cases were considered negative and $59.2 \%$ positive. The immunohistochemical staining also revealed a strong expression of PAR1 in the endothelial cells. PAR1 expression in tumor cells did not exhibit any significant correlation with any of the clinicopathological parameters, which included histological grade and lymph node metastasis, nor with patient survival, molecular subtype and/

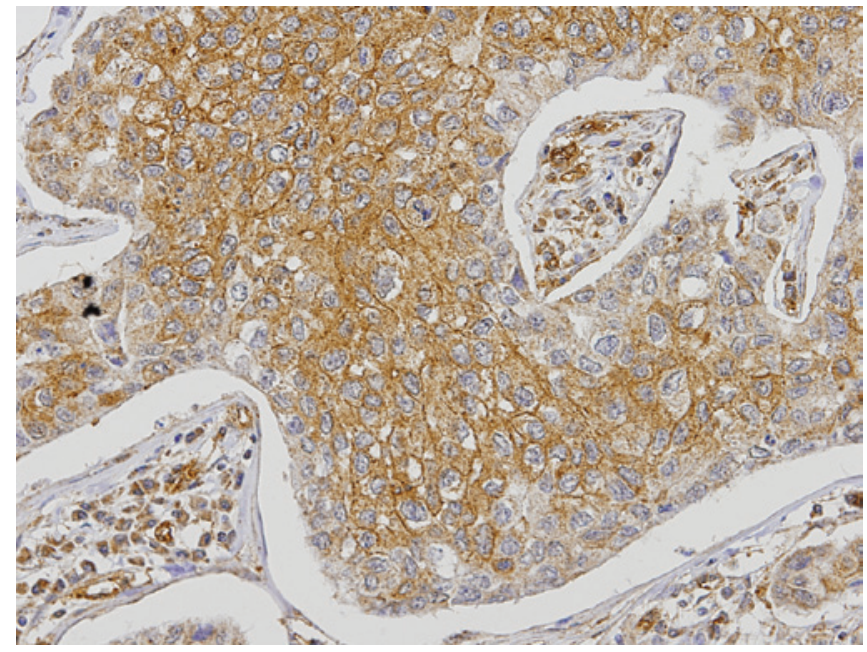

Figure 2. Positive FGFR1 immunostaining was observed. FGFR1 immunoreactivity was detected in the cytoplasm of the tumor cells (positive $>50 \%$ ), and in the stroma (magnification, $\mathrm{x} 20$ ).

or molecular markers, such as ER, PR, HER2, EGFR, Pcad, CK5, CK14, P63, P53 and vimentin (Table I). By contrast, statistically significant correlations were observed between the expression of PAR1 in the stroma and the molecular subtypes of breast cancer $(\underline{P}=0.0134), E R$ expression $(\underline{P}=0.0029), P R$ expression $(\underline{\mathrm{P}}=0.0263)$ and adhesion molecule $\mathrm{P}$-cadherin expression $(\underline{\mathrm{P}}=0.0440$; Table II). PAR1 expression in the stroma of the tumor was detected in a high percentage of cases among the basal and HER2 histological subtypes, as compared to the luminal subtype (Table III). Statistical analysis also revealed that a high percentage of ER cases $(>70 \%)$ with a negative expression exhibited a positive expression of PAR1 in the stroma, which was not observed with the ER-positive specimens. Similar results were observed between the expression of PAR1 in the stroma and the PR expression.

A significant statistical correlation was also observed between the expression of PAR1 in the stroma and the expression of Pcad, where approximately $70 \%$ of the Pcad-positive cases expressed PAR1. No significant statistical correlation was found between PAR1 expression in the tumor and patient survival (data not shown).

FGFR1 expression. The analysis of FGFR 1 expression in the tumor cells revealed that $3 \%$ of the cases were negative, $25.9 \%$ positive $<50 \%$ and $71.1 \%$ positive $>50 \%$ (Fig. 2). Expression of FGFR1 in tumor cells showed a significant correlation with tumor grade $(\mathrm{P}=0.0113)$ and with $\mathrm{P} 53$ expression ( $\mathrm{P}=0.0126$; Table IV). The statistical analysis also showed an increasing percentage of tumor cases expressing FGFR1 (positive $>50 \%$ ), from grades I to III. Results also showed that FGFR1 is highly expressed (positive $>50 \%$ ) in the tumor cells in $88.6 \%$ of the P53-positive cases and in $66 \%$ of the negative ones. A significant correlation with CK14 expression was observed $(\mathrm{P}=0.0253)$, although this correlation may have resulted from the small number of positive cases expressing CK14. No significant correlation was found between the expression of FGFR1 in the tumor and patient survival (data not shown). 
Table I. Correlation between PAR1 expression in the tumor cells and clinicopathological parameters.

\begin{tabular}{|c|c|c|c|c|c|}
\hline \multirow[b]{2}{*}{$\begin{array}{l}\text { Clinicopathological } \\
\text { parameters }\end{array}$} & \multirow[b]{2}{*}{$\mathrm{n}$} & \multicolumn{3}{|c|}{ PAR1 tumor } & \multirow[b]{2}{*}{ P-value } \\
\hline & & $\begin{array}{c}\text { Negative } \\
(5 \text { cases }) \%(n)\end{array}$ & $\begin{array}{l}\text { Positive }<50 \% \\
(17 \text { cases }) \%(n)\end{array}$ & $\begin{array}{c}\text { Positive }>50 \% \\
(189 \text { cases }) \%(n)\end{array}$ & \\
\hline \multicolumn{6}{|l|}{ Histological grade } \\
\hline I & 98 & $4.1(4)$ & $10.2(10)$ & $85.7(84)$ & \multirow[t]{3}{*}{0.3239} \\
\hline II & 78 & $0(0)$ & $7.7(6)$ & $92.3(72)$ & \\
\hline III & 29 & $3.4(1)$ & $3.4(1)$ & $93.1(27)$ & \\
\hline \multicolumn{6}{|c|}{ Lymph node metastasis } \\
\hline Positive & 93 & $3.2(3)$ & $5.4(5)$ & $91.4(85)$ & \multirow[t]{2}{*}{0.6419} \\
\hline Negative & 78 & $2.6(2)$ & $9(7)$ & $88.4(69)$ & \\
\hline \multicolumn{6}{|l|}{ Molecular subtype } \\
\hline Luminal & 129 & $3.1(4)$ & $4.7(6)$ & $92.2(119)$ & \multirow[t]{3}{*}{0.7403} \\
\hline Basal & 35 & $2.8(1)$ & $8.6(3)$ & $88.6(31)$ & \\
\hline HER2 & 20 & $0(0)$ & $10(2)$ & $90(18)$ & \\
\hline \multicolumn{6}{|l|}{ ER } \\
\hline Positive & 126 & $3.2(4)$ & $4.8(6)$ & $92.0(116)$ & \multirow[t]{2}{*}{0.0711} \\
\hline Negative & 85 & $1.2(1)$ & $12.9(11)$ & $85.9(73)$ & \\
\hline \multicolumn{6}{|l|}{ PR } \\
\hline Positive & 84 & $1.2(1)$ & $3.6(3)$ & $95.2(80)$ & \multirow[t]{2}{*}{0.0905} \\
\hline Negative & 127 & $3.2(4)$ & $11(14)$ & 85.8 (109) & \\
\hline \multicolumn{6}{|l|}{ HER 2} \\
\hline Positive & 26 & $3.8(1)$ & $7.7(2)$ & $88.5(23)$ & \multirow[t]{2}{*}{0.8812} \\
\hline Negative & 180 & $2.2(4)$ & $7.8(14)$ & $90(162)$ & \\
\hline \multicolumn{6}{|l|}{ EGFR } \\
\hline Positive & 13 & $0(0)$ & $0(0)$ & $100(13)$ & \multirow[t]{2}{*}{0.4465} \\
\hline Negative & 198 & $2.5(5)$ & $8.6(17)$ & $88.9(176)$ & \\
\hline \multicolumn{6}{|l|}{ Pcad } \\
\hline Positive & 52 & $0(0)$ & $9.6(5)$ & $90.4(47)$ & \multirow[t]{2}{*}{0.3969} \\
\hline Negative & 159 & $3.2(5)$ & $7.5(12)$ & $89.3(142)$ & \\
\hline \multicolumn{6}{|l|}{ CK5 } \\
\hline Positive & 51 & $2(1)$ & $5.9(3)$ & $92.1(47)$ & \multirow[t]{2}{*}{0.7818} \\
\hline Negative & 160 & $2.5(4)$ & $8.8(14)$ & $88.7(142)$ & \\
\hline \multicolumn{6}{|l|}{ CK14 } \\
\hline Positive & 4 & $0(0)$ & $25(1)$ & $75(3)$ & \multirow[t]{2}{*}{0.3696} \\
\hline Negative & 192 & $1(2)$ & $6.8(13)$ & $92.2(177)$ & \\
\hline \multicolumn{6}{|l|}{ P63 } \\
\hline Positive & 4 & $0(0)$ & $0(0)$ & $100(4)$ & 0.7888 \\
\hline Negative & 207 & $2.4(5)$ & $8.2(17)$ & $89.4(185)$ & \\
\hline P53 & & & & & \\
\hline Positive & 48 & $2.1(1)$ & $10.4(5)$ & $87.5(42)$ & 0.7863 \\
\hline Negative & 163 & $2.4(4)$ & $7.4(12)$ & $90.2(147)$ & \\
\hline Vimentin & & & & & \\
\hline Positive & 33 & $3(1)$ & $6.1(2)$ & $90.9(30)$ & 0.7041 \\
\hline Negative & 155 & $1.3(2)$ & $8.4(13)$ & $90.3(140)$ & \\
\hline
\end{tabular}

Regarding the stromal expression of FGFR1, results showed that only $9.6 \%$ of the cases were positive. Despite the low percentage of positive cases, significant correlations were observed between the expression of FGFR 1 in the stroma and histological grade $(\mathrm{P}=0.0238)$, breast cancer molecular subtypes $(\mathrm{p}=0.0063)$, ER expression $(\mathrm{P}=0.0127)$, Pcad expression $(\mathrm{P}=0.0041), \mathrm{P} 63$ expression $(0.0057)$ and $\mathrm{P} 53$ expression $(\mathrm{P}=0.0058$; Table $\mathrm{V})$. An increasing percentage of FGFR1-positive cases were observed, from cases of histological grades I to III. Additionally, a higher percentage 
Table II. Correlation between PAR1 expression in the stroma and clinipathological parameters.

\begin{tabular}{|c|c|c|c|c|}
\hline \multirow[b]{2}{*}{$\begin{array}{l}\text { Clinicopathological } \\
\text { parameters }\end{array}$} & \multirow[b]{2}{*}{$\mathrm{n}$} & \multicolumn{2}{|c|}{ PAR1 stroma } & \multirow[b]{2}{*}{ P-value } \\
\hline & & $\begin{array}{c}\text { Negative } \\
\text { (86 cases) \% (n) }\end{array}$ & $\begin{array}{c}\text { Positive } \\
\text { (125 cases) \% (n) }\end{array}$ & \\
\hline \multicolumn{5}{|l|}{ Histological grade } \\
\hline I & 98 & $48(47)$ & $52(51)$ & \multirow[t]{3}{*}{0.1007} \\
\hline II & 78 & $37.2(29)$ & $62.8(49)$ & \\
\hline III & 29 & $27.6(8)$ & $72.4(21)$ & \\
\hline \multicolumn{5}{|c|}{ Lymph node metastasis } \\
\hline Positive & 93 & $39.8(37)$ & $60.2(56)$ & \multirow[t]{2}{*}{0.8598} \\
\hline Negative & 78 & $38.5(30)$ & $61.5(48)$ & \\
\hline \multicolumn{5}{|l|}{ Molecular subtype } \\
\hline Luminal & 129 & $49.6(64)$ & $50.4(65)$ & \multirow[t]{3}{*}{0.0134} \\
\hline Basal & 35 & $22.9(8)$ & $77.1(27)$ & \\
\hline HER2 & 20 & $35(7)$ & $65(13)$ & \\
\hline \multicolumn{5}{|l|}{ ER } \\
\hline Positive & 126 & $49.2(62)$ & $50.8(64)$ & \multirow[t]{2}{*}{0.0029} \\
\hline Negative & 85 & $28.2(24)$ & $71.8(61)$ & \\
\hline \multicolumn{5}{|l|}{ PR } \\
\hline Positive & 84 & $50(42)$ & $50(42)$ & \multirow[t]{2}{*}{0.0263} \\
\hline Negative & 127 & $34.6(44)$ & $65.4(83)$ & \\
\hline \multicolumn{5}{|l|}{ HER2 } \\
\hline Positive & 26 & $42.3(11)$ & $57.7(15)$ & \multirow[t]{2}{*}{0.8226} \\
\hline Negative & 180 & $40(72)$ & 60 (108) & \\
\hline \multicolumn{5}{|l|}{ EGFR } \\
\hline Positive & 13 & $38.5(5)$ & $61.5(8)$ & \multirow[t]{2}{*}{0.8619} \\
\hline Negative & 198 & $40.9(81)$ & $59.1(117)$ & \\
\hline \multicolumn{5}{|l|}{ Pcad } \\
\hline Positive & 52 & $28.8(15)$ & $71.2(37)$ & \multirow[t]{2}{*}{0.0440} \\
\hline Negative & 159 & $44.6(71)$ & $55.4(88)$ & \\
\hline \multicolumn{5}{|l|}{ CK5 } \\
\hline Positive & 51 & $47.1(24)$ & $52.9(27)$ & \multirow[t]{2}{*}{0.2930} \\
\hline Negative & 160 & $38.8(62)$ & $61.2(98)$ & \\
\hline \multicolumn{5}{|l|}{ CK14 } \\
\hline Positive & 4 & $50(2)$ & $50(2)$ & \multirow[t]{2}{*}{0.6736} \\
\hline Negative & 192 & $39.6(76)$ & 60.4 (116) & \\
\hline \multicolumn{5}{|l|}{ P63 } \\
\hline Positive & 4 & $25(1)$ & $75(3)$ & 0.5173 \\
\hline Negative & 207 & $41.1(85)$ & $58.9(122)$ & \\
\hline P53 & & & & \\
\hline Positive & 48 & $31.2(15)$ & $68.8(33)$ & 0.1272 \\
\hline Negative & 163 & $43.6(71)$ & $56.4(92)$ & \\
\hline Vimentin & & & & \\
\hline Positive & 33 & $33.3(11)$ & $66.7(22)$ & 0.4350 \\
\hline Negative & 155 & $40.6(63)$ & $59.4(92)$ & \\
\hline
\end{tabular}

of FGFR1-positive cases in the basal and HER2 histological subtypes was observed when compared to the luminal subtype. It was also possible to observe a significant statistical correlation between ER expression and FGFR1 expression in the stroma, where the ER-negative cases exhibited a higher percentage of positive FGFR1 expression when compared to the ER-positive cases. FGFR1-positive cases (68) were negative for ER expression and $61 \%$ of the FGFR1-negative cases were positive for ER expression, suggesting an inverse correlation between the expression of the two molecules. 
Table III. Correlation between PAR1 expression in the tumor cells and stroma related to the expression of FGFR1 positive reaction in the tumor cells and stroma.

A, PAR1 tumor cells.

\begin{tabular}{lccc}
\hline & & \multicolumn{2}{c}{ PAR1 tumor cells } \\
\cline { 3 - 4 } IpX reaction & $\mathrm{n}$ & $\begin{array}{c}\text { Positive }<50 \% \\
(17 \text { cases }) \%(\mathrm{n})\end{array}$ & $\begin{array}{c}\text { Positive }>50 \% \\
(189 \text { cases }) \%(\mathrm{n})\end{array}$ \\
\hline FGFR1 tumor & 6 & & $66.7(4)$ \\
Negative & 48 & $33.3(2)$ & $87.5(42)$ \\
Positive $<50 \%$ & 139 & $12.5(6)$ & $92.8(129)$ \\
Positive $>50 \%$ & & $5(7)$ & 0.0511 \\
FGFR1 stroma & 19 & $5.3(1)$ & $94.7(18)$ \\
Positive & 174 & $8(14)$ & $90.3(157)$ \\
Negative & & & 0.7647 \\
\hline
\end{tabular}

B, PAR1 stroma.

\begin{tabular}{|c|c|c|c|c|}
\hline \multirow[b]{2}{*}{ IpX reaction } & \multirow[b]{2}{*}{$\mathrm{n}$} & \multicolumn{2}{|c|}{ PAR 1 stroma } & \multirow[b]{2}{*}{ P-value } \\
\hline & & $\begin{array}{c}\text { Negative } \\
(86 \text { cases }) \%(n)\end{array}$ & $\begin{array}{c}\text { Positive } \\
(125 \text { cases }) \%(n)\end{array}$ & \\
\hline \multicolumn{5}{|l|}{ FGFR1 tumor } \\
\hline Negative & 6 & $50(3)$ & $50(3)$ & 0.6947 \\
\hline Positive $<50 \%$ & 48 & $35.4(17)$ & $64.6(31)$ & \\
\hline Positive $>50 \%$ & 139 & $41(57)$ & $59(82)$ & \\
\hline \multicolumn{5}{|l|}{ FGFR1 stroma } \\
\hline Positive & 19 & $21.1(4)$ & $78.9(15)$ & 0.0773 \\
\hline Negative & 174 & $42(73)$ & $58(101)$ & \\
\hline
\end{tabular}

IpX, immunohistochemical reaction.

Another statistically significant correlation was found between FGFR1 and Pcad expression, revealing a higher percentage of Pcad-positive cases expressing FGFR1 as compared to their negative counterparts. The results also demonstrated a higher percentage of P53-positive cases expressing FGFR1 when compared to the P53-negative cases. A significant correlation between FGFR1 and P63 expression $(\mathrm{P}=0.0057)$ was also observed. Nonetheless, this correlation should be interpreted with caution due to the low number of positive cases expressing P63. No significant statistical correlations were found between the expression of FGFR1 in the stroma and patient survival (data not shown), nor between PAR1 and FGFR1.

Intratumoral microvessel density. iMVD evaluation was performed for 200 cases. The number of intratumoral blood vessels ranged between 0 and 47 . The cases were grouped according to the cut off: One group had an iMVD of $\leq 8.5$, the median iMVD, and a second group had an iMVD of >8.5. iMVD was correlated with the expression of PAR1 and FGFR1, in the tumor cells and stroma, as well as with several clinicopathological parameters and crucial breast cancer molecular markers (Table VI). A significant correlation was found between iMVD and the histological grade $(\mathrm{P}=0.022)$, with an inverse statistically significant correlation between breast cancer cases of grade III and iMVD. Regarding EGFR expression and iMVD, the results showed a higher percentage of $\mathrm{MMVD} \leq 8$ in positive EGFR cases when compared to iMVD >8.5 cases. A statistically significant correlation was also observed between iMVD and patient survival, showing that patients with an iMVD of $>8.5$ have better survival (data not shown). No significant correlations were observed between the iMVD with FGFR1 or PAR1 expression in the tumor cells or stroma.

\section{Discussion}

The analysis of PAR1 expression in a retrospective series of 224 formalin-fixed paraffin-embedded samples of ductal invasive breast carcinomas demonstrates, as suggested by previous studies, the expression of PAR1 in human malignant tumor cells as well as the cell types forming the tumor microenvironment, and no expression of PAR1 in the surrounding stromal fibroblasts of the normal and benign breast epithelial cells (19). PAR1 expression in tumor cells did not exhibit a significant correlation with any of the clinicopathological parameters 
Table IV. Correlation between FGFR1 expression in the tumor cells and clinicopathological parameters.

\begin{tabular}{|c|c|c|c|c|c|}
\hline \multirow[b]{2}{*}{$\begin{array}{l}\text { Clinicopathological } \\
\text { parameters }\end{array}$} & \multirow[b]{2}{*}{$\mathrm{n}$} & \multicolumn{3}{|c|}{ FGFR1 tumor } & \multirow[b]{2}{*}{ P-value } \\
\hline & & $\begin{array}{c}\text { Negative } \\
\text { (6 cases) \% (n) }\end{array}$ & $\begin{array}{l}\text { Positive }<50 \% \\
\text { (51 cases) \% (n) }\end{array}$ & $\begin{array}{c}\text { Positive }>50 \% \\
(140 \text { cases) } \% \text { (n) }\end{array}$ & \\
\hline \multicolumn{6}{|l|}{ Histological grade } \\
\hline I & 89 & $1.1(1)$ & $37.1(33)$ & $61.8(55)$ & 0.0113 \\
\hline II & 74 & $5.4(4)$ & $16.2(12)$ & $78.4(58)$ & \\
\hline III & 28 & $3.6(1)$ & $14.3(4)$ & $82.1(23)$ & \\
\hline \multicolumn{6}{|l|}{$\begin{array}{l}\text { Lymph node } \\
\text { metastasis }\end{array}$} \\
\hline Positive & 84 & $1.2(1)$ & $26.2(22)$ & $72.6(61)$ & 0.3065 \\
\hline Negative & 75 & $5.3(4)$ & $22.7(17)$ & $72(54)$ & \\
\hline \multicolumn{6}{|l|}{ Molecular subtype } \\
\hline Luminal & 118 & $1.7(2)$ & $27.1(32)$ & $71.2(84)$ & 0.2303 \\
\hline Basal & 32 & $6.2(2)$ & $12.5(4)$ & $81.3(26)$ & \\
\hline HER2 & 20 & $0(0)$ & $20(4)$ & $80(16)$ & \\
\hline \multicolumn{6}{|l|}{ ER } \\
\hline Positive & 115 & $1.8(2)$ & $27.8(32)$ & $70.4(81)$ & 0.3744 \\
\hline Negative & 82 & $4.9(4)$ & $23.2(19)$ & $71.9(59)$ & \\
\hline \multicolumn{6}{|l|}{ PR } \\
\hline Positive & 75 & $1.4(1)$ & $25.3(19)$ & $73.3(55)$ & 0.5305 \\
\hline Negative & 122 & $4.1(5)$ & $26.2(32)$ & $69.7(85)$ & \\
\hline \multicolumn{6}{|l|}{ HER 2} \\
\hline Positive & 25 & $0(0)$ & $16(4)$ & $84(21)$ & 0.2574 \\
\hline Negative & 167 & $3.6(6)$ & $27.5(46)$ & $68.9(115)$ & \\
\hline \multicolumn{6}{|l|}{ EGFR } \\
\hline Positive & 13 & $0(0)$ & $15.4(2)$ & $84.6(11)$ & 0.5024 \\
\hline Negative & 184 & $3.3(6)$ & $26.6(49)$ & 70.1 (129) & \\
\hline \multicolumn{6}{|l|}{ Pcad } \\
\hline Positive & 50 & $0(0)$ & $20(10)$ & $80(40)$ & 0.1580 \\
\hline Negative & 147 & $4.1(6)$ & $27.9(41)$ & $68(100)$ & \\
\hline \multicolumn{6}{|l|}{ CK5 } \\
\hline Positive & 50 & $4(2)$ & $22(11)$ & $74(37)$ & 0.7143 \\
\hline Negative & 147 & $2.7(4)$ & $27.2(40)$ & $70.1(103)$ & \\
\hline \multicolumn{6}{|l|}{ CK14 } \\
\hline Positive & 4 & $25(1)$ & $0(0)$ & $75(3)$ & 0.0253 \\
\hline Negative & 188 & $2.7(5)$ & $27.1(51)$ & $70.2(132)$ & \\
\hline \multicolumn{6}{|l|}{ P63 } \\
\hline Positive & 4 & $0(0)$ & $25(1)$ & $75(3)$ & 0.9350 \\
\hline Negative & 193 & $3.1(6)$ & $25.9(50)$ & 80 (137) & \\
\hline \multicolumn{6}{|l|}{ P53 } \\
\hline Positive & 44 & $2.3(1)$ & $9.1(4)$ & $88.6(39)$ & 0.0126 \\
\hline Negative & 153 & $3.3(5)$ & 30.7 (47) & $66(101)$ & \\
\hline \multicolumn{6}{|l|}{ Vimentin } \\
\hline Positive & 33 & $6.1(2)$ & $18.2(6)$ & $75.7(25)$ & 0.4315 \\
\hline Negative & 151 & $2.7(4)$ & $25.8(39)$ & $71.5(108)$ & \\
\hline
\end{tabular}

analysed, including histological grade, lymph node metastasis, patient survival, molecular subtype and the expression of several molecular markers, such as ER, PR, HER2, EGFR, Pcad, CK5, CK14, P63, P53 and vimentin.
The present study has shown the absence of statistically significant correlations of PAR1 expressed in the tumor cells. Specifically, the statistical analysis showed a significant association between the expression of PAR1 in the stroma and 
Table V. Correlation between FGFR1 expression in the stroma and clinicopathological parameters.

\begin{tabular}{|c|c|c|c|c|}
\hline \multirow[b]{2}{*}{$\begin{array}{l}\text { Clinicopathological } \\
\text { parameters }\end{array}$} & \multirow[b]{2}{*}{$\mathrm{n}$} & \multicolumn{2}{|c|}{ FGFR1 stroma } & \multirow[b]{2}{*}{$\mathrm{P}$-value } \\
\hline & & $\begin{array}{c}\text { Negative } \\
\text { (178 cases) \% (n) }\end{array}$ & $\begin{array}{c}\text { Positive } \\
\text { (19 cases) \% (n) }\end{array}$ & \\
\hline \multicolumn{5}{|l|}{ Histological grade } \\
\hline I & 89 & $95.5(85)$ & $4.5(4)$ & \multirow[t]{3}{*}{0.0238} \\
\hline II & 74 & $87.8(65)$ & $12.2(9)$ & \\
\hline III & 28 & $78.6(22)$ & $21.4(6)$ & \\
\hline \multicolumn{5}{|l|}{$\begin{array}{l}\text { Lymph node } \\
\text { metastasis }\end{array}$} \\
\hline Positive & 84 & $88.1(74)$ & $11.9(10)$ & \multirow[t]{2}{*}{0.2593} \\
\hline Negative & 75 & $93.3(70)$ & $6.7(5)$ & \\
\hline \multicolumn{5}{|l|}{ HER 2} \\
\hline Positive & 25 & $88(22)$ & $12(3)$ & \multirow[t]{2}{*}{0.7056} \\
\hline Negative & 167 & $90.4(151)$ & $9.6(6)$ & \\
\hline \multicolumn{5}{|l|}{ Molecular subtype } \\
\hline Luminal & 118 & $94.1(111)$ & $5.9(7)$ & \multirow[t]{3}{*}{0.0063} \\
\hline Basal & 32 & 75 (24) & $25(8)$ & \\
\hline HER2 & 20 & $85(17)$ & $15(3)$ & \\
\hline \multicolumn{5}{|l|}{ ER } \\
\hline Positive & 115 & 94.8 (109) & $5.2(6)$ & \multirow[t]{2}{*}{0.0127} \\
\hline Negative & 82 & $84.1(69)$ & $15.9(13)$ & \\
\hline \multicolumn{5}{|l|}{ PR } \\
\hline Positive & 75 & $93.3(70)$ & $6.7(5)$ & \multirow[t]{2}{*}{0.2669} \\
\hline Negative & 122 & 88.5 (108) & $11.5(14)$ & \\
\hline \multicolumn{5}{|l|}{ EGFR } \\
\hline Positive & 13 & $76.9(10)$ & $23.1(3)$ & \multirow[t]{2}{*}{0.0896} \\
\hline Negative & 184 & $91.3(168)$ & $8.7(16)$ & \\
\hline \multicolumn{5}{|l|}{ Pcad } \\
\hline Positive & 50 & $80(40)$ & $20(10)$ & \multirow[t]{2}{*}{0.0041} \\
\hline Negative & 147 & $93.9(138)$ & $6.1(9)$ & \\
\hline \multicolumn{5}{|l|}{ CK5 } \\
\hline Positive & 50 & $90(45)$ & $10(5)$ & \multirow[t]{2}{*}{0.9215} \\
\hline Negative & 147 & $90.5(133)$ & $9.5(14)$ & \\
\hline \multicolumn{5}{|l|}{ CK14 } \\
\hline Positive & 4 & $100(4)$ & $0(0)$ & \multirow[t]{2}{*}{0.5156} \\
\hline Negative & 188 & $90.4(170)$ & $9.6(18)$ & \\
\hline \multicolumn{5}{|l|}{ P63 } \\
\hline Positive & 4 & $50(2)$ & $50(2)$ & 0.0057 \\
\hline Negative & 193 & $91.2(176)$ & $8.8(17)$ & \\
\hline P53 & & & & \\
\hline Positive & 44 & $79.5(35)$ & $20.5(9)$ & 0.0058 \\
\hline Negative & 153 & $93.5(143)$ & $6.5(10)$ & \\
\hline Vimentin & & & & \\
\hline Positive & 33 & $84.8(28)$ & $15.2(5)$ & 0.2518 \\
\hline Negative & 151 & $91.4(138)$ & $8.6(13)$ & \\
\hline
\end{tabular}

more aggressive histological subtypes of breast cancer, more specifically with the basal and HER2 subtypes. Stromal cells, such as fibroblasts and inflammatory cells recruited to the tumor microenvironment highly expressed MMPs, and recent studies suggest that the MMP1 in the stromal-tumor microen- vironment is capable of altering the behaviour of cancer cells through PAR1 to promote cell migration and invasion (11).

The fact that a high percentage of cases negative for ER and PR expression are positive for PAR 1 expression in the stroma also suggests an association with poor prognosis (21). 
Table VI. Correlation between intratumoral microvessel density and clinicopathological parameters.

\begin{tabular}{|c|c|c|c|c|}
\hline \multirow[b]{2}{*}{$\begin{array}{l}\text { Clinicopathological } \\
\text { parameters }\end{array}$} & \multirow[b]{2}{*}{$\mathrm{n}$} & \multicolumn{2}{|c|}{ iMVD } & \multirow[b]{2}{*}{ P-value } \\
\hline & & $\begin{array}{c}\leq 8.5 \\
\%(100)\end{array}$ & $\begin{array}{c}>8.5 \\
\%(100)\end{array}$ & \\
\hline \multicolumn{5}{|l|}{ Histological grade } \\
\hline $\mathrm{I}$ & 94 & $44.7(42)$ & $55.3(52)$ & 0.022 \\
\hline II & 73 & $46.6(34)$ & $53.4(39)$ & \\
\hline III & 27 & $74.1(20)$ & $25.9(7)$ & \\
\hline \multicolumn{5}{|c|}{ Lymph node metastasis } \\
\hline Negative & 77 & $44.2(34)$ & $55.8(43)$ & 0.609 \\
\hline Positive & 83 & $48.2(40)$ & $51.8(43)$ & \\
\hline \multicolumn{5}{|l|}{ Molecular subtype } \\
\hline Luminal A & 117 & $55.6(65)$ & $44.4(52)$ & 0.417 \\
\hline Luminal B & 7 & $28.6(2)$ & $71.4(5)$ & \\
\hline HER2 & 4 & $50.0(2)$ & $50.0(2)$ & \\
\hline Basal & 52 & $46.2(24)$ & $53.8(28)$ & \\
\hline \multicolumn{5}{|l|}{ ER } \\
\hline Negative & 79 & $44.3(35)$ & $55.7(44)$ & 0.193 \\
\hline Positive & 121 & $53.7(65)$ & $46.3(56)$ & \\
\hline \multicolumn{5}{|l|}{ PR } \\
\hline Negative & 123 & $45.5(56)$ & $54.5(67)$ & 0.110 \\
\hline Positive & 77 & $57.1(44)$ & $42.9(33)$ & \\
\hline \multicolumn{5}{|l|}{ HER2 } \\
\hline Negative & 172 & $50.0(86)$ & $50.0(86)$ & 0.981 \\
\hline Positive & 27 & $52.2(14)$ & $47.8(13)$ & \\
\hline \multicolumn{5}{|l|}{ EGFR } \\
\hline Negative & 189 & $48.1(91)$ & $51.9(98)$ & 0.030 \\
\hline Positive & 11 & $81.8(9)$ & $18.2(2)$ & \\
\hline \multicolumn{5}{|l|}{ CK5 } \\
\hline Negative & 150 & $53.3(80)$ & $46.7(70)$ & 0.102 \\
\hline Positive & 50 & $40.0(20)$ & $60.0(30)$ & \\
\hline \multicolumn{5}{|l|}{ CK14 } \\
\hline Negative & 187 & $49.2(92)$ & $50.8(95)$ & 0.307 \\
\hline Positive & 4 & $75.0(3)$ & $25.0(1)$ & \\
\hline \multicolumn{5}{|l|}{ P-Cad } \\
\hline Negative & 149 & $47.7(71)$ & $52.3(78)$ & 0.256 \\
\hline Positive & 51 & $56.9(29)$ & $43.1(22)$ & \\
\hline \multicolumn{5}{|l|}{ P63 } \\
\hline Negative & 196 & $50.0(98)$ & $50.0(98)$ & 1.000 \\
\hline Positive & 4 & $50.0(2)$ & $50.0(2)$ & \\
\hline \multicolumn{5}{|l|}{ P53 } \\
\hline Negative & 157 & $50.3(79)$ & $49.7(78)$ & 0.863 \\
\hline Positive & 43 & $48.8(21)$ & $51.2(22)$ & \\
\hline \multicolumn{5}{|l|}{ FGFR1 tumor } \\
\hline Negative & 6 & $50.0(3)$ & $50.0(3)$ & 0.706 \\
\hline Positive $<50 \%$ & 48 & $43.8(21)$ & $56.2(27)$ & \\
\hline Positive $>50 \%$ & 136 & $50.7(69)$ & $49.3(67)$ & \\
\hline \multicolumn{5}{|l|}{ FGFR1 stroma } \\
\hline Negative & 172 & $50.0(86)$ & $50.0(86)$ & 0.370 \\
\hline Positive & 18 & $38.9(7)$ & $61.1(11)$ & \\
\hline \multicolumn{5}{|l|}{ PAR1 tumor } \\
\hline Negative & 4 & $50.0(2)$ & $50.0(2)$ & 0.721 \\
\hline Positive $<50 \%$ & 17 & $41.2(7)$ & $58.8(10)$ & \\
\hline Positive $>50 \%$ & 173 & $51.4(89)$ & $48.6(84)$ & \\
\hline
\end{tabular}


Furthermore, the finding that a high percentage of cases positive for Pcad expression are also positive for PAR1 expression in the stroma suggests an association between PAR1 and invasive behaviour, since Pcad expression has been strongly associated with a high histological grade of ductal in situ breast carcinoma and poor survival, and has also shown a strong inverse correlation with ER expression in two types of breast carcinoma (in situ and invasive) $(22,23)$. These results showed a strong association between the expression of PAR1 in the stroma and several clinicopathological parameters associated with more aggressive breast cancers, with worse response to treatment and consequently poor prognosis, highlighting the importance of the microenvironment in tumor expression, suggesting a potential role of PAR1 in autocrine and paracrine mechanisms of breast cancer progression (24).

Most of our results related to PAR1 expression are not in agreement with a previous study that demonstrated a significant correlation between the expression of PAR 1 in breast cancer and tumor grade in the presence of positive axillary lymph nodes in a series of 75 breast carcinoma specimens (16). Nonetheless, these differences may be explained by a different classification used for assessment of PAR 1 expression in the two studies and the number of cases analyzed in each study.

PAR1 expression levels are directly correlated with degree of invasiveness in both primary breast tissue specimens and established cancer cell lines (25). This finding supports the results observed for PAR1 expression in the stroma and suggest active involvement of the former protein in a neoplastic development scenario. More studies are required to precisely explain the role of PAR1 in more aggressive tumor behaviour and poor patient prognosis.

As for FGFR1 expression, significant correlations were found between FGFR1 expression in tumor cells and tumor grade and P53 expression, showing an association between FGFR 1 and parameters of cancer aggressiveness (2). These results are coherent due to the well-known correlation between P53 isoforms and solid malignant tumor progression (26). Furthermore, the significant correlations observed between FGFR1 expression in the stroma and the histological grade, molecular subtypes, ER, Pcad and P53 expression, emphasize the association of FGFR1 with more aggressive breast cancer phenotypes previously suggested by in vitro models $(27,28)$.

It was previously demonstrated that when core 2 of the 8p11.2-p12 is amplified, FGFR1 gene shows increased levels of mRNA and protein expression, as FGFR1 signalling is required for the survival of breast cancer cells harbouring FGFR I amplification (29). Furthermore, FGFR1 amplification was observed in up to $10 \%$ of breast carcinomas and patient survival analysis revealed FGFRl amplification to be an independent prognostic factor for survival, more specifically in patients with ER-positive tumors, where FGFRI amplification was the strongest independent predictor of poor outcome, suggesting that this gene is a useful therapeutic target for a subgroup of breast cancer patients with FGFRl gene amplification (30). We were careful to include the patient's outcome in the statistical analyses. To the best of our knowledge, this is the first study to consider the correlation of PAR1 and FGFR1 expression in a large breast cancer cohort. Patient survival information was not available for all patients, limiting the evaluation of survival curves.
The tissue-specific expression of FGFs and FGFRs is critical factor in regulating FGFR signalling pathways and malignant transformation (31). FGF1 and FGFR1 were also demonstrated to be notably expressed in breast cancer cells. FGFR1 is also expressed in normal breast tissues but not FGF1, which suggests that breast cancer cells are able to release FGF1 and express FGFR1 in a neoplastic scenario, leading to a tumoral mass growing not only by a paracrine, but also by an autocrine mechanism (30). FGFR 1 is able to directly activate both proliferation and survival signals (anti-apoptotic effects) within mammary epithelium to rapidly induce hyperplastic lesions and regulate MMP secretion (19). This finding suggests a crucial role for FGFR1 during tumor progression and prognosis and may explain, in part, the results obtained for FGFR1 in the tumor and stroma cells, reported in the present study.

Intratumoral angiogenesis, commonly assessed by determination of iMVD, has been suggested as a prognostic factor in solid tumors, as it has been shown on numerous occasions that higher iMVD is associated with poorer prognosis (32). Tissue microarrays are not the preferred option for determining iMVD; however, we opted for this method in order to maintain the same pattern of analyses for all cases. Our results did not show a statistically significant correlation between iMVD and clinicopathological parameters associated with cancer aggressiveness. The statistical significant inverse correlations we observed with histological grade III and for positive EGFR are debatable. Approximately $75 \%$ of grade III cases showed an iMVD of $<8.5$. Essentially, a minority of studies have not demonstrated an association between higher iMVD and poor prognosis. The apparent paradox between our findings and those of previous studies may be explained by several factors such as the lack of a standardized iMVD assessment (vessel counting and statistical analysis), use of different endothelial markers and immunostaining techniques with different specificity and sensitivity, the different size cohorts, different cut off and inadequate follow up (32). Regarding breast cancer, the controversies are even more pronounced since no significant differences in tumor vascularity with different molecular subtypes have been found (33).

In conclusion, the results have shown that PAR1 and FGFR1 expression in breast carcinomas are correlated to several clinicopathological parameters of tumor behaviour, suggesting an association of PAR1 and FGFR1 with the more aggressive breast cancers, with possible worse response to treatment and consequently poor prognosis, emphasizing the importance of the microenvironment in tumor progression.

\section{Acknowledgements}

CICECO is an Associated Laboratory of the Portuguese Ministry of Science, Technology and Higher Education, being financed by Pest-C/CTM/LA0011/2011.

\section{References}

1. Ferlay J, Shin HR, Bray F, Forman D, Mathers C and Parkin DM: Estimates of worldwide burden of cancer in 2008: GLOBOCAN 2008. Int J Cancer 127: 2893-2917, 2010.

2. Weigelt B and Reis-Filho JS: Histological and molecular types of breast cancer: is there a unifying taxonomy? Nat Rev Clin Oncol 6: 718-730, 2009 
3. Weigelt B, Horlings HM, Kreike B, et al: Refinement of breast cancer classification by molecular characterization of histological special types. J Pathol 216: 141-150, 2008.

4. Hanahan D and Weinberg RA: Hallmarks of cancer: the next generation. Cell 144: 646-674, 2011.

5. Pusztai L: Current status of prognostic profiling in breast cancer. Oncologist 13: 350-360, 2008.

6. Yin YJ, Salah Z, Maoz M, et al: Oncogenic transformation induces tumour angiogenesis: a role for PAR1 activation. FASEB J 17: 163-174, 2003.

7. Winter SF, Acevedo VD, Gangula RD, et al: Conditional activation of FGFR1 in the prostate epithelium induces angiogenesis with concomitant differential regulation of Ang-1 and Ang-2. Oncogene 26: 4897-4907, 2007.

8. Agarwal A, Covic L, Sevigny LM, et al: Targeting a metalloprotease-PAR1 signaling system with cell-penetrating pepducins inhibits angiogenesis, ascites, and progression of ovarian cancer. Mol Cancer Ther 7: 2746-2757, 2008.

9. Vu TK, Hung DT, Wheaton VI and Coughlin SR: Molecular cloning of a functional thrombin receptor reveals a novel proteolytic mechanism of receptor activation. Cell 64: 1057-1068, 1991.

10. O'Brien PJ, Prevost N, Molino M, Hollinger MK, Woolkalis MJ, Woulfe DS and Brass LF: Thrombin responses in human endothelial cells. Contributions from receptors other than PAR1 include the transactivation of PAR2 by thrombin-cleaved PAR1. J Biol Chem 275: 13502-13509, 2000.

11. Boire A, Covic L, Agarwal A, et al: PAR1 is a matrix metalloprotease-1 receptor that promotes invasion and tumourigenesis of breast cancer cells. Cell 120: 303-313, 2005 .

12. Bassus S, Herkert O, Kronemann N, et al: Thrombin causes vascular endothelial growth factor expression in vascular smooth muscle cells: role of reactive oxygen species. Arterioscler Thromb Vasc Biol 21: 1550-1555, 2001.

13. Duarte M, Kolev V, Soldi R, et al: Thrombin induces rapid PAR1-mediated non-classical FGF1 release. Biochem Biophys Res Commun 350: 604-609, 2006.

14. Delafontaine P, Anwar A, Lou H and Ku L: G-protein coupled and tyrosine kinase receptors: evidence that activation of the insulin-like growth factor I receptor is required for thrombin induced mitogenesis of rat aortic smooth muscle cells. J Clin Invest 97: 139-145, 1996.

15. Rauch BH, Millette E, Kenagy RD, et al: Thrombin- and factor Xa-induced DNA synthesis is mediated by transactivation of fibroblast growth factor receptor-1 in human vascular smooth muscle cells. Circ Res 94: 340-345, 2004.

16. Hernandez NA, Correa E, Avila EP, et al: PAR1 is selectively over expressed in high grade breast cancer patients: a cohort study. J Transl Med 7: 47, 2009.

17. D'Andrea MR, Derian CK, Santulli RJ and Andrade-Gordon P. Differential expression of protease activated receptors-1 and -2 in stromal fibroblasts of normal, benign, and malignant human tissues. Am J Pathol 158: 2031-2041, 2001.
18. Schwertfeger KL: Fibroblast growth factors in development and cancer: insights from the mammary and prostate glands. Curr Drug Targets 10: 632-644, 2009.

19. Welm BE, Freeman KW, Chen M, et al: Inducible dimerization of FGFR1: development of a mouse model to analyze progressive transformation of the mammary gland. J Cell Biol 157: 703-714, 2002.

20. Marinho A, Soares R, Ferro J, et al: Angiogenesis in breast cancer is related to age but not to other prognostic parameters. Pathol Res Pract 193: 267-273, 1997.

21. Brenton JD, Carey LA, Ahmed AA and Caldas C: Molecular classification and molecular forecasting of breast cancer: ready for clinical application? J Clin Oncol 23: 7350-7360, 2005.

22. Paredes J, Correia AL, Ribeiro AS, et al: Breast carcinomas that co-express E- and P-cadherin are associated with p120catenin cytoplasmic localisation and poor patient survival. J Clin Pathol 61: 856-862, 2008.

23. Paredes J, Milanezi F, Viegas L, et al: P-cadherin expression is associated with high-grade ductal carcinoma in situ of the breast. Virchows Arch 440: 16-21, 2002.

24. Yang E, Boire A, Agarwal A, et al: Blockade of PAR1 signaling with cell-penetrating pepducins inhibits Akt survival pathways in breast cancer cells and suppresses tumour survival and metastasis. Cancer Res 69: 6223-6231, 2009.

25. Even-Ram S, Uziely B, Cohen P, et al: Thrombin receptor overexpression in malignant and physiological invasion processes. Nat Med 4: 909-914, 1998.

26. Bourdon JC: p53 and its isoforms in cancer. Br J Cancer 97: 277-282, 2007.

27. Suyama K, Shapiro I, Guttman M and Hazan RB: A signaling pathway leading to metastasis is controlled by $\mathrm{N}$-cadherin and the FGF receptor. Cancer Cell 2: 301-314, 2002.

28. Xian W, Schwertfeger KL, Vargo-Gogola T and Rosen JM: Pleiotropic effects of FGFR1 on cell proliferation, survival, and migration in a 3D mammary epithelial cell model. J Cell Biol 171: 663-673, 2005.

29. Reis-Filho JS, Simpson PT, Turner NC, et al: FGFR1 emerges as a potential therapeutic target for lobular breast carcinomas. Clin Cancer Res 12: 6652-6662, 2006.

30. Elbauomy Elsheikh S, Green AR, Lambros MB, et al: FGFR1 amplification in breast carcinomas: a chromogenic in situ hybridisation analysis. Breast Cancer Res 9: R23, 2007.

31. Grose R and Dickson C: Fibroblast growth factor signaling in tumourigenesis. Cytokine Growth Factor Rev 16: 179-186, 2005.

32. Hasan J, Byers R and Jayson GC: Intratumoural microvessel density in human solid tumours. Br J Cancer 86: 1566-1577, 2002.

33. Lopes N, Sousa B, Vieira D, et al: Vessel density assessed by endoglin expression in breast carcinomas with different expression profiles. Histopathology 55: 594-599, 2009. 